\title{
In Vitro Enamel Remineralization Efficacy of Calcium Silicate-Sodium Phosphate-Fluoride Salts versus NovaMin Bioactive Glass, Following Tooth Whitening
}

\author{
Hatem M. El-Damanhoury Nesrine A. Elsahn²,3 \\ ${ }^{1}$ Department of Preventive and Restorative Dentistry, \\ College of Dental Medicine, University of Sharjah, Sharjah, \\ United Arab Emirates \\ ${ }^{2}$ Department of Clinical Sciences, College of Dentistry, Ajman \\ University, Ajman, United Arab Emirates \\ ${ }^{3}$ Department of Operative Dentistry, Faculty of Dentistry, Cairo \\ University, Cairo, Egypt \\ ${ }^{4}$ Dental Biomaterials Research Group, Sharjah Institute for Medical \\ Research, University of Sharjah, Sharjah, United Arab Emirates \\ ${ }^{5}$ College of Dental Medicine, University of Sharjah, Sharjah, \\ United Arab Emirates
}

Soumya Sheela ${ }^{4}$ Talal Bastaty ${ }^{5}$

\author{
Address for correspondence Hatem El-Damanhoury, BDS, MS, \\ PhD, Room M28-129, College of Dental Medicine, University \\ of Sharjah, P.O. Box: 27272, Sharjah, United Arab Emirates \\ (e-mail: hdamanhoury@sharjah.ac.ae).
}

Eur J Dent:2021;15:515-522

\section{Abstract \\ Keywords \\ - bleaching \\ - enamel \\ - remineralization \\ - scanning electron microscopy \\ - energy dispersive $\mathrm{X}$-ray analysis \\ - calcium \\ silicate-sodium phosphate-fluoride \\ - NovaMin}

Objectives This study aimed to evaluate the effect of in-office bleaching on the enamel surface and the efficacy of calcium silicate-sodium phosphate-fluoride salt (CS) and NovaMin bioactive glass (NM) dentifrice in remineralizing bleached enamel.

Materials and Methods Forty extracted premolars were sectioned mesio-distally, and the facial and lingual enamel were flattened and polished. The samples were equally divided into nonbleached and bleached with 38\% hydrogen peroxide (HP). Each group was further divided according to the remineralization protocol $(n=10)$; no remineralization treatment (nontreated), CS, or NM, applied for 3 minutes two times/ day for 7 days, or CS combined with NR- 5 boosting serum (CS+NR-5) applied for 3 minutes once/day for 3 days. The average Knoop hardness number (KHN) and surface roughness (utilizing atomic force microscopy) were measured. Surface topography/ elemental analysis was analyzed by using scanning electron microscopy/energy dispersive X-ray analysis. All the tests were performed at baseline, after bleaching, and following each remineralization protocol. Data were statistically analyzed by two-way analysis of variance and Bonferroni post hoc multiple comparison tests $(\alpha=0.05)$.

Results HP significantly reduced KHN and increased roughness $(p<0.05)$. All remineralization materials increased the hardness and reduced the surface roughness after bleaching except NM, which demonstrated significantly increased roughness $(p<0.05)$. $\mathrm{Ca} / \mathrm{P}$ ratio decreased after bleaching $(p<0.05)$, and following treatment, $C S$ and CS+NR-5 exhibited higher remineralization capacity in comparison to NM $(p<0.05)$.

Conclusion Although none of the material tested was able to reverse the negative effect of high-concentration in-office HP on enamel completely, the remineralization efficacy of CS and CS+NR-5 was superior to that of NM.
DOI https://doi.org/

$10.1055 / \mathrm{s}-0040-1722484$ ISSN 1305-7456.

\footnotetext{
(C) 2021. European Journal of Dentistry.

This is an open access article published by Thieme under the terms of the Creative Commons Attribution-NonDerivative-NonCommercial-License, permitting copying and reproduction so long as the original work is given appropriate credit. Contents may not be used for commercial purposes, or adapted, remixed, transformed or built upon. (https://creativecommons.org/licenses/by-nc-nd/4.0/).

Thieme Medical and Scientific Publishers Pvt. Ltd. A-12, 2nd Floor, Sector 2, Noida-201301 UP, India
} 


\section{Introduction}

Among the aesthetic management modalities of vital and nonvital discolored teeth, dental bleaching has proven to be a highly conservative and simple treatment option. At present, several bleaching agents are commercially available and are mainly based on different concentrations of hydrogen peroxide (HP) or carbamide peroxide (CP). These products are available for use at home or in the dental office, possibly aided by various types of light sources to intensify the oxidation reaction. ${ }^{1}$

The process of bleaching teeth involves free radicals generation such as oxygen and perhydroxyl because of the decomposition of HP. The presence of these radicals generates an oxidation-reduction reaction. ${ }^{2}$ Due to their exceedingly electrophilic nature, free radicals diffuse through the matrices of enamel and dentin to bombard the pigment molecules and ultimately gain stability, and this is possible due to the permeability of dental tissue. Following this reaction, the organic macromolecules-of which the pigments are formed-are broken down into less complex, smaller, and lighter molecules. ${ }^{3}$ Due to the unspecific nature of this reaction, several studies have investigated its undesirable effects on tooth structure such as mineral loss and alterations to surface topography which can, in turn, alter the biomechanical properties of enamel. ${ }^{4,5}$

Morphological changes of enamel surface were reported, mainly due to the erosive nature of the bleaching process. ${ }^{6}$ Bleaching affects the organic components of enamel and produces changes in the mineral phase, which ultimately creates visible morphological changes on the enamel surface. ${ }^{7,8} \mathrm{~A}$ study by Ushigome et al described that HP selectively erodes rod sheath areas while CP causes mineral dissolution and decalcification, which results in etch-like erosion of surface and subsurface enamel. ${ }^{9}$ The erosive effects are in view of the acidity of the bleaching agents, where some bleaching products have been reported to have a $\mathrm{pH}$ as low as $2.4 .^{10}$

The application of remineralizing agents was found to restore the morphological defects caused by bleaching. ${ }^{11}$ Currently, among the available remineralization promoting agents, fluoride-based formulations remain the most commonly used anti-erosive materials. They enhance the precipitation of calcium phosphates and in turn promote the formation of fluoro-hydroxyapatite crystals in dental tissues. ${ }^{12}$

A dentifrice containing calcium silicate, sodium phosphate, and fluoride salts (CSSPF) has been introduced. This technology was first proposed to supplement the natural process of mineralization by human saliva, which was possible by providing auxiliary calcium and phosphate that nucleates hydroxyapatite (HAP) formation. This mechanism seems to promote the remineralization and repair of softened enamel and aids in protecting enamel from acid challenges. ${ }^{13}$ The CSSPF-based toothpaste was introduced with a boosting serum, which was claimed to enhance the power of enamel remineralization.

Another class of commercially available agents that have been indicated in the treatment of dental hypersensitivity and enamel remineralization is bioactive glass, specifically, NovaMin. Primarily, NovaMin is a ceramic material that consists of amorphous sodium-calcium-phosphosilicate as a powder of fine particle size that is highly reactive in water. NovaMin works in two mechanisms. One mechanism is that the fine powder itself is capable of occluding dentinal tubules,,$^{14}$ and the second is by its reaction when exposed to the tooth's aqueous environment. The production of calcium and phosphate ions from the glass is brought about by the rapid exchange of particles between the sodium ions in NovaMin and hydrogen cations from the aqueous environment of the tooth. ${ }^{15}$ The release of sodium at primary exposure of the material to water leads to a transitory and localized increase in $\mathrm{pH}$. This effect encourages the precipitation of the supplementary calcium and phosphate ions delivered by the NovaMin ultimately forming a layer of calcium phosphate. This layer then crystalizes into carbonate-enriched hydroxyapatite (HCA). ${ }^{16}$ The newly formed HCA combines with the residual NovaMin particles, remineralizing the enamel surface and hinders further demineralization. ${ }^{14}$

The remineralization of bleached enamel has been scarcely tackled in the literature. Therefore, this study was conducted to investigate the remineralizing capacity of two anti-erosive/ remineralizing agents (namely CSSPF and NovaMin bioactive glass) on the bleached enamel, by assessing their effect on the enamel surface hardness and roughness. The null hypothesis being that the tested remineralizing agents have no effect on the surface hardness and surface roughness of the bleached enamel.

\section{Materials and Methods}

\section{Samples Preparation}

The compositions of the tested materials are listed in - Table 1. Forty sound human premolars extracted for orthodontic purposes were used in this study after ethical approval by the University of Sharjah research ethics committee and after patient consent. The teeth were examined under a stereomicroscope for the presence of cracks, decay, or any other defect, and teeth with defects were excluded from the study. Any soft tissues remnants were removed by using an ultrasonic scaler. The roots were sectioned at the cemento-enamel junction using a high-speed dental handpiece and a diamond bur and then the pulp tissues were removed. The crown of each tooth was sectioned mesio-distally into two halves using a diamond saw (Isomet 1000; Buehler, Lake Bluff, Illinois, United States) to obtain 80 specimens. The specimens were embedded in self-cured acrylic resin (Fastray, Harry J. Bosworth Co.; Skokie, Illinois, United States) with the enamel surface facing upward. The enamel surfaces were polished using a grinding/polishing machine (EcoMet 30; Buehler, Lake Bluff, Illinois, United States) with 400, 600, and 1200 grit water-cooled sandpaper discs to attain flat enamel surfaces and then polished using Synthetic Polishing Cloth (Super-Snap Buff Disk, Shofu Dental Corp.; Kyoto, Japan) soaked with $1 \mu \mathrm{m}$ diamond suspension (Buehler). After polishing, the specimens were cleaned in an ultrasonic bath with deionized water for 5 min. 
The enamel surface microhardness (baseline KHN) was determined by using a microhardness tester (HMV-2; Shimadzu Corporation, Tokyo, Japan). Five indentations per sample were performed at distances of $100 \mu \mathrm{m}$ from each other using a microindentor (Knoop diamond, $100 \mathrm{~g} / 15 \mathrm{sec}$. An average of five readings for each specimen was recorded as its KHN value. According to KHN values at the baseline, data from 10 specimens $(n=10)$ were averaged so that the average baseline $\mathrm{KHN}$ in the eight experimental groups was nearly equal ( - Table 2 ).

\section{Bleaching of Enamel}

Four groups (nonbleached groups) were randomly selected and did not receive any bleaching treatment. In contrast, the other four groups (bleached groups) were treated with a $38 \%$
HP bleaching gel (Opalescence R Boost, Ultradent Products, Inc.; South Jordan, Utah, United States). Bleaching of the enamel samples was done following the manufacturer's instructions, and each sample was subjected to three consecutive 20-min applications. Following each bleaching gel application, the sample surface was washed with a strong stream of air and water for $20 \mathrm{sec}$. After the third session, the bleached surfaces were resubmitted to KHN microhardness test to obtain the degree of softening.

\section{Remineralization of Enamel}

The nonbleached groups (1-4) and bleached groups (5-8) were randomly assigned to four different remineralization protocols. Group 1 (nonbleached [NT]) served as a negative control (NT), and Group 5 served as a bleached positive

Table 1 Materials tested in the study

\begin{tabular}{|c|c|c|c|c|}
\hline Product & Manufacturer & Composition & $\mathrm{pH}$ value & Lot \\
\hline Opalescence Boost & $\begin{array}{l}\text { Ultradent Products, } \\
\text { South Jordan, Utah, } \\
\text { United States }\end{array}$ & $\begin{array}{l}38 \% \text { hydrogen peroxide, } 3 \% \text { potassium nitrate, and } \\
1.1 \% \text { fluoride ions ( } 10,000 \mathrm{ppm})\end{array}$ & $7.52^{30}$ & B069 \\
\hline $\begin{array}{l}\text { Sensodyne Repair \& } \\
\text { Protect }\end{array}$ & $\begin{array}{l}\text { GSK, Middlesex, } \\
\text { United Kingdom }\end{array}$ & $\begin{array}{l}\text { Glycerin, PEG-8, silica, calcium sodium phosphosilicate } \\
\text { (NovaMin), sodium lauryl sulfate, aroma, titanium } \\
\text { dioxide, carbomer, potassium acesulfame, limonene, } \\
\text { contains sodium monofluorophosphate } 1.08 \% \mathrm{w} / \mathrm{w} \\
\text { (1,450 ppm fluoride) }\end{array}$ & $8.63^{23}$ & B7034603 \\
\hline $\begin{array}{l}\text { Regenerate Enamel } \\
\text { Science }\end{array}$ & $\begin{array}{l}\text { Unilever; London, } \\
\text { United Kingdom }\end{array}$ & $\begin{array}{l}\text { Glycerin, calcium silicate, PEG-8, hydrated silica, } \\
\text { trisodium phosphate, sodium phosphate, aqua, } \\
\text { PE-60, sodium lauryl sulfate, sodium monofluoro- } \\
\text { phosphate, aroma flavour, synthetic fluorphlogo- } \\
\text { pite, sodium saccharin, polyacrylic acid, tin oxide, } \\
\text { limonene }\end{array}$ & $9.02^{23}$ & 4175 CCC \\
\hline $\begin{array}{l}\text { Regenerate Enamel } \\
\text { Science -Advanced } \\
\text { Enamel Serum }\end{array}$ & $\begin{array}{l}\text { Unilever; London, } \\
\text { United Kingdom }\end{array}$ & $\begin{array}{l}\text { NR-5 serum: glycerin, calcium silicate, peg-8, triso- } \\
\text { dium phosphate, sodium phosphate, aqua, PEG-60, } \\
\text { sodium lauryl sulfate, sodium monoflourophosphate, } \\
\text { aroma/flavour, hydrated silica, synthetic fluorphlogo- } \\
\text { pite, sodium saccharin, polyacrylic acid, tin oxide, } \\
\text { CI } 77891 \text {, Limonene } \\
\text { Activator gel: Aqaua, glycerin, cellulose, gum, } \\
\text { sodium flouride, benzyl alchohol, ethylexylglycerin, } \\
\text { phenoxyethanol, Cl } 42090\end{array}$ & Not available & $42038 C A$ \\
\hline
\end{tabular}

Table 2 Mean Knoop microhardness number ( \pm standard deviation) of bleached and nonbleached enamel surfaces after no treatment, treatment with sensodyne repair \& protect, regenerate enamel science, or regenerate enamel-advanced enamel serum

\begin{tabular}{|c|c|c|c|c|}
\hline & Treatment & Baseline (KHN) & Bleached (KHN) & Re-min (KHN) \\
\hline \multirow[t]{4}{*}{ Nonbleached } & NT & $342.7 \pm 34.2$ & & $321.4 \pm 33.4^{A}$ \\
\hline & NM & $341.4 \pm 53.6$ & & $332.5 \pm 22.5^{\mathrm{A}}$ \\
\hline & CS & $346.6 \pm 35.4$ & & $338.5 \pm 23.9^{A}$ \\
\hline & CS+NR-5 & $347.3 \pm 42.1$ & & $328.8 \pm 43.2^{\mathrm{A}}$ \\
\hline \multirow[t]{4}{*}{ Bleached } & NT & $346.1 \pm 29.9^{a}$ & $281.1 \pm 47.3^{b}$ & $272.1 \pm 33.7^{\mathrm{B}, \mathrm{b}}$ \\
\hline & NM & $348.5 \pm 21.0^{\mathrm{a}}$ & $274.9 \pm 25.4^{b}$ & $293.6 \pm 36.2^{\mathrm{B}, \mathrm{b}}$ \\
\hline & CS & $343.0 \pm 42.8^{\mathrm{a}}$ & $272.2 \pm 37.6^{b}$ & $324.2 \pm 42.6^{\mathrm{A}, \mathrm{a}}$ \\
\hline & CS+NR-5 & $349.1 \pm 46.3^{a}$ & $276.5 \pm 43.5^{b}$ & $335.0 \pm 31.5^{\mathrm{A}, \mathrm{a}}$ \\
\hline
\end{tabular}

Abbreviations: CS, regenerate enamel science; NR-5, regenerate enamel boosting serum; KHN, Knoop hardness number; NM, sensodyne repair and protect; NT, no treatment.

Note: Within a column, different superscript capital letters indicate a significant difference $(p<0.05)$. Within a row, different superscript small letters indicate a significant difference $(p<0.05)$. 
control. Both groups were kept in artificial saliva for $24 \mathrm{~h}$ and did not receive any remineralization treatment. Groups 2 and 6 were subjected to remineralization treatment with NovaMin-based toothpaste (NM), and groups 3, 4, 7, and 8 were subjected to CSSPF-based toothpaste (CS). Group 4 and 8 received additional treatment with NR-5 boosting serum (CS+NR-5).

The remineralization procedure in groups $2,3,4,6$, 7 , and 8 , consisted of 3-min application of a solution of toothpaste/water in 1:2 ratio two times a day for 7 days. The toothpaste solution was applied by using a soft brush and minimal pressure. In Groups 4 and 8, after treatment with the toothpaste, the remineralizing NR-5 gel was prepared by mixing equal amounts of NR-5 serum with the activator gel (1:1 ratio) on a glass slab with a plastic mixing stick. This mixture was applied to the specimens' surfaces and kept undisturbed for 3 minutes once daily for 3 consecutive days.

After each application of toothpaste or serum gel, the specimens were rinsed in distilled water for $5 \mathrm{sec}$ and kept in the freshly prepared artificial saliva in an incubator at $37^{\circ} \mathrm{C}$. The artificial saliva was prepared following Holland's protocol, ${ }^{17}$ (composition: $0.4 \mathrm{~g} \mathrm{NaCl}, 0.4 \mathrm{~g} \mathrm{KCl}, 0.795 \mathrm{~g} \mathrm{CaCl}_{2} \cdot 2 \mathrm{H}_{2} \mathrm{O}, 0.78 \mathrm{~g}$ $\mathrm{NaH}_{2} \mathrm{PO}_{4} \cdot 2 \mathrm{H}_{2} \mathrm{O}, 0.005 \mathrm{~g} \mathrm{Na} 2 \mathrm{~S} \cdot 9 \mathrm{H}_{2} \mathrm{O}, 1 \mathrm{~g}$ urea, and $1,000 \mathrm{~mL}$ distilled water), and the $\mathrm{pH}$ of the saliva was adjusted at $7 \pm 0.2$.

\section{Knoop Surface Hardness Test}

As mentioned earlier, the Knoop surface microhardness (KHN) of the enamel surfaces before and after bleaching was recorded. Subsequently, the test was repeated following each remineralization treatment. The number of indentions per sample and the testing procedures were standardized throughout the study. At each testing point, data of each experimental group from 10 specimens were averaged.

\section{Surface Roughness Test}

Forty additional enamel samples were prepared and polished, as mentioned above. The baseline surface roughness of each specimen was evaluated under an atomic force microscope (AFM; Flex-Axiom, Nanosurf AG, Liestal, Switzerland). AFM was used in a noncontact mode by using an AFM cantilever with magneto-resistive sensors integrated into its tip (7 $\mu \mathrm{m}$ thickness, $225 \mu \mathrm{m}$ length, and $38 \mu \mathrm{m}$ width) under a constant force of $48 \mathrm{~N} / \mathrm{m}$.

On each polished surface, four standardized rectangular spots $(25 \times 25 \mu \mathrm{m}$ each) were scanned. The changes in the vertical position provide the height of the images, registered as bright and dark regions. The tip-specimens distance was maintained stable through constant oscillation amplitude (set-point amplitude). AFM micrographs were analyzed by using a scanning probe microscopy data analysis software (C3000 control software; version 3.7.2.8, Nanosurf AG, Liestal, Switzerland). The average surface roughness (Sa), valley depth (lowest value - Sv), and peak height (highest value - Sp) of the unbleached enamel surfaces were recorded as the baseline readings and were expressed as numeric values in nanometers.

Then the samples were divided into eight equal groups ( $n=5)$ according to the experimental design mentioned above. The surface roughness measurements were repeated after each allocated treatment for each experimental group.

\section{Micromorphological and Energy Dispersive X-Ray Analysis}

Three representative samples from each experimental group were dehydrated in a desiccator containing dehydrated silica gel at room temperature for $24 \mathrm{~h}$. The micromorphological analysis was performed after sputter coating with 100 Å Gold-Palladium (EMS 7620 Mini Sputter Coater; Electron Microscopy Sciences, Hatfield, Pennsylvania, United States) to create a conductive specimen surface and to reduce electron charging, which may reduce the quality of the image. Observations were performed under different magnifications up to $\times 5000$ by using a scanning electron microscope (SEM) (VEGA3 XM-TESCAN; Kohoutovice, Czech Republic) operating at $20 \mathrm{kV}$ acceleration voltage and 10 to $25 \mathrm{~mm}$ working distance.

SEM-coupled energy-dispersive X-ray spectroscopy (AZtecLive, Oxford Instruments; Abingdon, United Kingdom) operating at a take-off angle of 35 degrees with map mode was conducted at the same operating voltage. The average main elements \% weight content of the experimental groups (calcium and phosphorus), and the calcium to phosphorus ration $(\mathrm{Ca} / \mathrm{P})$ per each group was calculated.

\section{Statistical Analysis}

Results were analyzed with statistical software (SPSS software; version 15.0, SPSS Inc., Chicago, Illinois, United States) by using a two-way analysis of variance and Bonferroni post hoc multiple comparison tests $(\alpha=0.05)$ to determine the effect of the variables (bleaching and the type of the remineralizing agent) on the surface hardness and surface roughness of enamel, and to determine the effect of bleaching and type of the remineralizing agent on the surface hardness and surface roughness of enamel

\section{Results}

The results of the Knoop microhardness test of the experimental groups are listed in - Table 2 . The post hoc test revealed a statistically significant difference $(p<0.05)$ between the surface hardness of the enamel specimens before and after bleaching, with a significant reduction in the enamel surface hardness by 18 to $21 \%$. NM showed inferior ability to restore the reduced surface hardness of enamel, compared with CS and CS+NR-5 groups, which showed no significant difference $(p>0.05)$ between the KHN of enamel at baseline and after remineralization with these two groups.

The results of the AFM surface roughness test of the experimental groups are listed in - Table 3 and illustrated in - Fig. 1 . A statistically significant difference $(p<0.05)$ between the surface roughness of the enamel specimens before and after bleaching was evident, with more than threefold increase in the enamel surface roughness. Treatment of enamel with NM significantly increased the surface roughness of both bleached and nonbleached enamel $(p<0.05)$. Meanwhile, the 
Table 3 Mean area surface roughness in $\mathrm{nm}$ ( \pm standard deviation) of bleached and nonbleached enamel surfaces after no treatment, treatment with sensodyne repair \& protect, regenerate enamel science, or regenerate enamel-advanced enamel serum

\begin{tabular}{|l|l|l|l|l|}
\hline & Treatment & Baseline $(\mathbf{n m})$ & Bleached $(\mathrm{nm})$ & Re-min $(\mathrm{nm})$ \\
\hline \multirow{5}{*}{ Nonbleached } & NT & $42.6 \pm 8.6$ & & $42.4 \pm 5.5^{\mathrm{A}}$ \\
\cline { 2 - 5 } & NM & $46.7 \pm 7.4^{\mathrm{a}}$ & & $84.0 \pm 7.6^{\mathrm{B}, \mathrm{b}}$ \\
\cline { 2 - 5 } & CS & $44.7 \pm 5.9$ & & $51.6 \pm 7.4^{\mathrm{A}}$ \\
\cline { 2 - 5 } & CS+NR-5 & $42.9 \pm 6.8$ & & $54.7 \pm 8.4^{\mathrm{A}}$ \\
\hline & NT & $44.3 \pm 5.1^{\mathrm{a}}$ & $136 \pm 9.6^{\mathrm{b}}$ & $144.7 \pm 9.4^{\mathrm{C}, \mathrm{b}}$ \\
\cline { 2 - 5 } & NM & $40.8 \pm 8.3^{\mathrm{a}}$ & $130 \pm 7.6^{\mathrm{b}}$ & $173.6 \pm 11.3^{\mathrm{D}, \mathrm{c}}$ \\
\cline { 2 - 5 } & CS & $44.2 \pm 9.2^{\mathrm{a}}$ & $140 \pm 8.2^{\mathrm{b}}$ & $89.7 \pm 8.2^{\mathrm{B}, \mathrm{c}}$ \\
\cline { 2 - 5 } & CS+NR-5 & $46.3 \pm 8.4^{\mathrm{a}}$ & $142 \pm 9.3^{\mathrm{b}}$ & $82.4^{\mathrm{b}} \pm 9.1^{\mathrm{B}, \mathrm{c}}$ \\
\hline
\end{tabular}

Abbreviations: CS, regenerate enamel science; NR-5, regenerate enamel boosting serum; NM, sensodyne repair and protect; NT, no treatment. Note: Within a column, different superscript capital letters indicate a significant difference $(p<0.05)$. Within a row, different superscript small letters indicate a significant difference $(p<0.05)$.

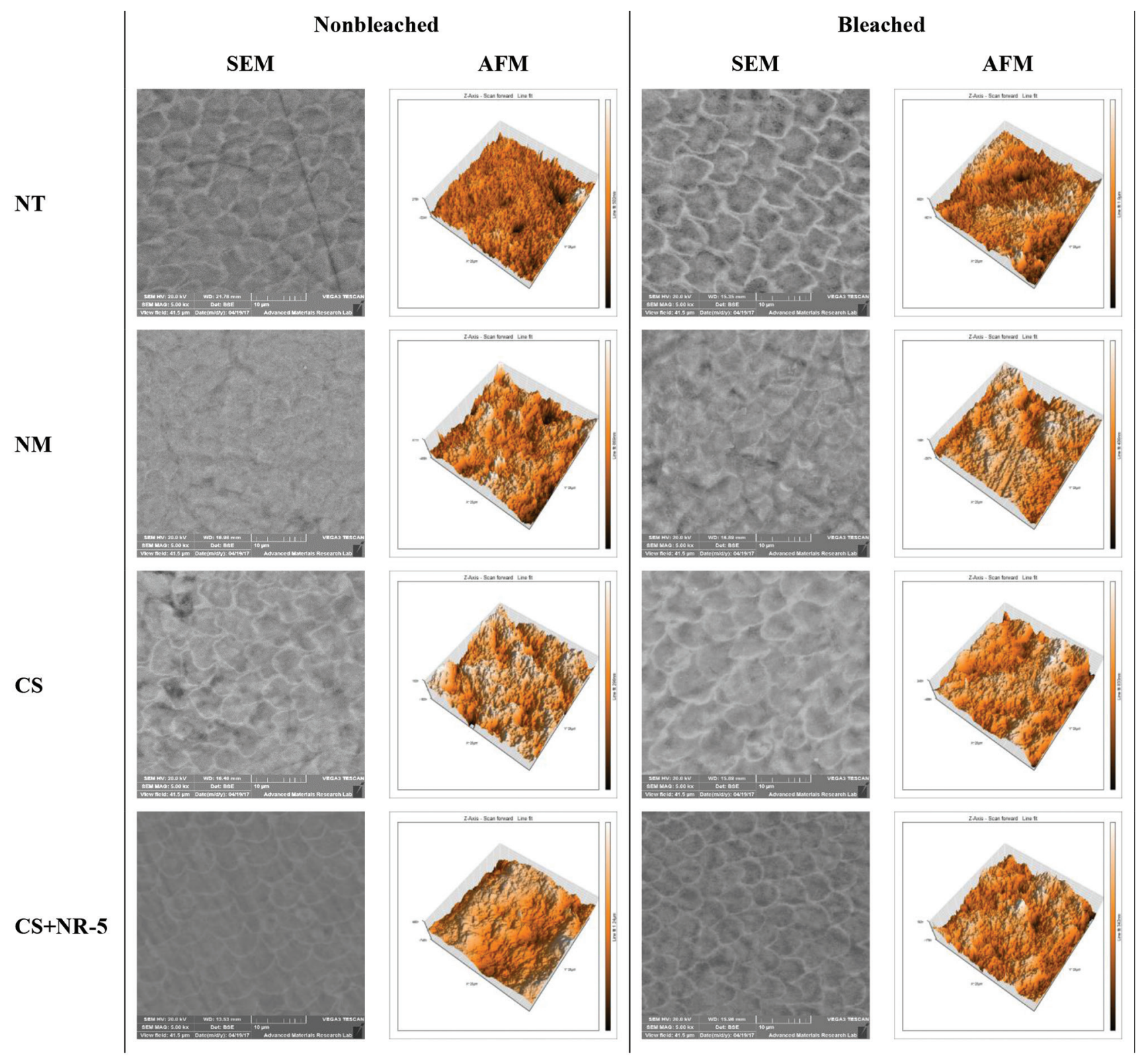

Fig. 1 Scanning electron microscope and atomic force microscope microphotographs of bleached and nonbleached enamel surface after no treatment, or treatment with sensodyne repair and protect (NM), regenerate enamel science (CS) or CS followed by regenerate enamel boosting serum (CS+NR-5). 
CS and CS+NR-5 groups showed a significant decrease in surface roughness of the bleached enamel $(p<0.05)$.

The average element content (wt\%) of calcium, and phosphorus, and $\mathrm{Ca} / \mathrm{P}$ ratio of the experimental groups are listed in - Table 4. Within the nonbleached groups, there was no significant difference in the main element wt\% and the $\mathrm{Ca} / \mathrm{P}$ ratio between NT and the treated groups. A significant reduction in the $\mathrm{Ca} / \mathrm{P}$ ratio was recorded after bleaching $(p<0.05)$. In comparison to the PC group, an increase in the $\mathrm{Ca} / \mathrm{P}$ ratios was measured for the bleached groups after treatment with NM, CS, and CS+NR-5.

Sample SEM microphotographs of the investigated groups are presented in - Fig. 1. The surface morphological analysis showed a typical honeycomb appearance in all the bleached groups, the pattern is similar to that of the acid-etched enamel. Compared with the NT bleached group, this pattern was less evident after treatment with the tested remineralizing agents. None of these treatments were able to completely reverse the effect of bleaching, compared with the nonbleached treated groups.

\section{Discussion}

Teeth whitening, although comparatively prevalent, is still considered controversial regarding the morphological changes brought upon enamel, accompanying the procedure. The significance of this concern has manifested as the recommendation of using a remineralizing agent after bleaching. The effectiveness of the various remineralizing agents remains in question. In this study, the effectiveness of CSSPF and NovaMin-based dentifrice to remineralize bleached human enamel were tested, using the Knoop microhardness test and analyzing mean surface roughness values with an AFM. This study has observed that the tested remineralizing products have positively affected the microhardness and surface roughness of the bleached enamel; thus, the null hypothesis tested should be rejected.

Conflicting results were reported in the literature regarding the effect of bleaching on enamel. Cadenaro et al, in an in vivo study, found no significant effect of 38\% HP in-office bleaching on the roughness of enamel. ${ }^{18}$ In contrast, Hosoya et $\mathrm{al}^{19}$ reported morphological changes to enamel following bleaching with a high concentration of HP, and concluded a strong association between bleaching and the increased enamel roughness and Streptococcus mutans adhesion. While Basting et $\mathrm{al}^{20}$ reported a significant reduction by 10 to $23 \%$ KHN of bleached enamel, Rodrigues et $\mathrm{al}^{4}$ reported a $47 \%$ reduction in KHN of bleached enamel. These inconsistencies may be due to differences in study design, namely, the magnitude and time of loading used in the hardness testing or the different concentration and time of application of the bleaching agent.

In the current study, a significant reduction in surface hardness and an increase in surface roughness of enamel was found after bleaching, and these results were confirmed by the SEM morphological analysis and the AFM microradiographs (-Fig. 1). Our findings are in agreement with a study by Lewinstein et al, ${ }^{21}$ who reported a reduction of $13 \% \mathrm{KHN}$ for home bleaching and up to $25 \%$ for in-office bleaching.

These changes in surface roughness and hardness after enamel bleaching can be attributed to either the low $\mathrm{pH}$ or high concentration of the peroxides used with the in-office bleaching. The bleaching material used in this study has a $\mathrm{pH}$ value of 7.52, which is considered neutral or slightly alkaline. Therefore, the increased porosity of enamel can be attributed to the effect of the nascent oxygen of the high concentration HP rather than the acidic erosion of the hydroxyapatite. ${ }^{22,23}$

The EDX elemental analysis (- Table 4 ) revealed a significant reduction in the $\mathrm{Ca} / \mathrm{P}$ ratio of the bleached enamel in comparison to the baseline readings, which in agreement with the findings of several previous studies. ${ }^{24,25}$

The application of CSSPF showed a significant increase in microhardness compared with values obtained after bleaching. This finding is consistent with other investigations; an in situ study by Joiner et al placed acid-challenged tooth enamel inserts onto patients' partial dentures. The inserts were then treated with four different agents. The study found that the combination of calcium, phosphate, and fluoride ions from

Table 4 Energy dispersive X-ray analysis elemental analysis of Ca and P (wt\%) and Ca/P ratio of bleached and nonbleached enamel surfaces after no treatment, treatment with sensodyne repair \& protect, regenerate enamel science, or regenerate enamel-advanced enamel serum

\begin{tabular}{|l|l|l|l|l|}
\hline \multirow{2}{*}{ Nonbleached } & \multirow{2}{*}{ Treatment } & \multicolumn{3}{|l|}{ Element composition (wt \%) } \\
\cline { 2 - 5 } & & Ca & P & Ca \\
\hline & NT & $37.80 \pm 1.3^{\mathrm{a}}$ & $17.20 \pm 0.7^{\mathrm{a}}$ & $2.20 \pm 0.2^{\mathrm{a}}$ \\
\cline { 2 - 5 } & NM & $36.20 \pm 1.1^{\mathrm{a}}$ & $17.60 \pm 0.9^{\mathrm{a}}$ & $2.06 \pm 0.1^{\mathrm{b}}$ \\
\cline { 2 - 5 } & CS & $36.10 \pm 1.1^{\mathrm{a}}$ & $17.10 \pm 1.3^{\mathrm{a}}$ & $2.11 \pm 0.1^{\mathrm{b}}$ \\
\cline { 2 - 5 } & CS+NR-5 & $35.30 \pm 0.5^{\mathrm{a}}$ & $16.40 \pm 0.8^{\mathrm{a}}$ & $2.15 \pm 0.1^{\mathrm{b}}$ \\
\hline \multirow{3}{*}{ Bleached } & NT & $20.00 \pm 1.2^{\mathrm{b}}$ & $11.70 \pm 1.0^{\mathrm{b}}$ & $1.71 \pm 0.1^{\mathrm{c}}$ \\
\cline { 2 - 5 } & NM & $25.00 \pm 1.0^{\mathrm{c}}$ & $11.50 \pm 1.1^{\mathrm{b}}$ & $2.17 \pm 0.1^{\mathrm{b}}$ \\
\cline { 2 - 5 } & CS & $25.80 \pm 0.8^{\mathrm{c}}$ & $11.90 \pm 0.9^{\mathrm{b}}$ & $2.20 \pm 0.1^{\mathrm{a}}$ \\
\hline & CS+NR-5 & $24.50 \pm 1.1^{\mathrm{c}}$ & $11.00 \pm 0.8^{\mathrm{b}}$ & $2.23 \pm 0.1^{\mathrm{a}}$ \\
\hline
\end{tabular}

Abbreviations: CS, regenerate enamel science; CS+NR-5, regenerate enamel boosting serum; NM, sensodyne repair and protect; NT, no treatment. Note: Within a column, different superscript letters indicate a significant difference $(p<0.05)$. 
the sodium fluoride and mono-fluoro-phosphate resulted in an increase in microhardness, which was consistent along with all evaluation intervals. ${ }^{26}$ Moreover, another experiment conducted by Hornby et al studied the effectiveness of CSSPF versus other agents under conditions of $\mathrm{pH}$ cycling within the normal range of demineralization and remineralization, and they concluded that CSSPF proved significant effectiveness versus different formulations included in their study. ${ }^{27}$

The superior effects of CSSPF can be attributed to its mode of action, which includes multiple mechanisms. Calcium silicate has the ability to release calcium ions in an acidic environment, which deprives the area of protons while simultaneously enriching the local calcium concentration. This mechanism increases the degree of saturation and theoretically inhibits demineralization. Moreover, in the presence of phosphate salts, calcium silicate has been shown to deposit directly onto the enamel surface and maintain its affinity even after rinsing. This affinity, aided by the presence of phosphate ions, results in the nucleation and eventual precipitation of HAP on the surface of the calcium silicate particles. This nucleation takes place after only one exposure and at $\mathrm{pH}$ values as low as $4 .{ }^{13}$ Moreover, the newly formed HAP may act as the first defense against future acid attacks, keeping the underlying enamel protected. These explanations were supported by the findings of the EDX elemental analysis, where an increase in the calcium and phosphate wt\% was recorded after treatment with CS. Finally, the efficacy of fluoride alone, in remineralization, is directly dependent on the availability of calcium and phosphate at the site of action. ${ }^{28}$ This dependency is absent in calcium silicate and phosphate technologies.

It is worth noting that none of the tested materials was able to reverse the effect of bleaching on enamel roughness completely. This may be attributed to the negative effect of the abrasive particles that are added to them to increase their mechanical ability to remove plaque. ${ }^{29,30}$

\section{Conclusion}

Physical and chemical structural changes brought upon enamel must be a matter of serious concern to any practitioner utilizing bleaching procedures for improved aesthetics. Also, knowledge of the different remineralizing agents and their efficacy is useful in enhancing treatment outcome and long-term patient satisfaction. The application of CSSPF for $3 \mathrm{~min}$, two times a day and for 7 days was able to significantly re-harden acideroded enamel and greatly decrease its surface roughness.

\section{Funding}

None.

\section{Conflict of Interest}

None declared.

\section{Acknowledgement}

The authors would like to acknowledge Professor Hussien Al Awadi, Director of the Advanced Materials Research Center, University of Sharjah, and Eng. Mohammed Shameer for their help with SEM/EDX and AFM analysis, and Dr. Sherine
Stino, Bio-Materials Department, Faculty of Dentistry, Cairo University, for her help with data collection.

\section{References}

1 Rastelli ANS, Nicolodelli G, Romano RA, et al. After bleaching enamel remineralization using a bioactive glass-ceramic (BioSilicate) Biomed Glas 2016;2(1):1-9

2 Tredwin CJ, Naik S, Lewis NJ, Scully C. Hydrogen peroxide tooth-whitening (bleaching) products: review of adverse effects and safety issues. Br Dent J 2006;200(7):371-376

3 Markowitz K. Pretty painful: why does tooth bleaching hurt? Med Hypotheses 2010;74(5):835-840

4 Rodrigues JA, Oliveira GPF, Amaral CM. Effect of thickener agents on dental enamel microhardness submitted to at-home bleaching. Braz Oral Res 2007;21(2):170-175

5 Haywood VB, Leech T, Heymann HO, Crumpler D, Bruggers K. Nightguard vital bleaching: effects on enamel surface texture and diffusion. Quintessence Int 1990;21(10):801-804

6 Miranda CB, Pagani C, Benetti AR, Matuda F da S. Evaluation of the bleached human enamel by scanning electron microscopy. J Appl Oral Sci 2005;13(2):204-211

7 Bitter NC. A scanning electron microscopy study of the effect of bleaching agents on enamel: a preliminary report. J Prosthet Dent 1992;67(6):852-855

8 Elfallah HM, Swain MV. A review of the effect of vital teeth bleaching on the mechanical properties of tooth enamel. $\mathrm{N} \mathrm{Z}$ Dent J 2013;109(3):87-96

9 Ushigome T, Takemoto S, Hattori M, Yoshinari M, Kawada E, Oda Y. Influence of peroxide treatment on bovine enamel surface-cross-sectional analysis. Dent Mater J 2009;28(3):315-323

10 Dominguez JA, Bittencourt B, Michel M, Sabino N, Gomes JC, Gomes OMM. Ultrastructural evaluation of enamel after dental bleaching associated with fluoride. Microsc Res Tech 2012;75(8):1093-1098

11 Attin T, Kielbassa AM, Schwanenberg M, Hellwig E. Effect of fluoride treatment on remineralization of bleached enamel. J Oral Rehabil 1997;24(4):282-286

12 Coceska E, Gjorgievska E, Coleman NJ, et al. Enamel alteration following tooth bleaching and remineralization. J Microsc 2016;262(3):232-244

13 Sun Y, Li X, Deng Y, et al. Mode of action studies on the formation of enamel minerals from a novel toothpaste containing calcium silicate and sodium phosphate salts. J Dent 2014;42(Suppl 1) :S30-S38

14 Gjorgievska E, Nicholson JW. Prevention of enamel demineralization after tooth bleaching by bioactive glass incorporated into toothpaste. Aust Dent J 2011;56(2):193-200

15 Andersson $\mathrm{OH}$, Kangasniemi I. Calcium phosphate formation at the surface of bioactive glass in vitro. J Biomed Mater Res 1991;25(8):1019-1030

16 Zhong JP, Greenspan DC, Feng JW. A microstructural examination of apatite induced by Bioglass in vitro. J Mater Sci Mater Med 2002;13(3):321-326

17 Holland RI. Corrosion testing by potentiodynamic polarization in various electrolytes. Dent Mater 1992;8(4):241-245

18 Cadenaro M, Navarra CO, Mazzoni A, et al. An in vivo study of the effect of a 38 percent hydrogen peroxide in-office whitening agent on enamel. J Am Dent Assoc 2010;141(4):449-454

19 Hosoya N, Honda K, lino F, Arai T. Changes in enamel surface roughness and adhesion of Streptococcus mutans to enamel after vital bleaching. J Dent 2003;31(8):543-548

20 Basting RT, Rodrigues AL Jr, Serra MC. The effects of seven carbamide peroxide bleaching agents on enamel microhardness over time. J Am Dent Assoc 2003;134(10):1335-1342 
21 Lewinstein I, Fuhrer N, Churaru N, Cardash H. Effect of different peroxide bleaching regimens and subsequent fluoridation on the hardness of human enamel and dentin. J Prosthet Dent 2004;92(4):337-342

22 Hegedüs C, Bistey T, Flóra-Nagy E, Keszthelyi G, Jenei A. An atomic force microscopy study on the effect of bleaching agents on enamel surface. J Dent 1999;27(7):509-515

23 João-Souza SH, Lussi A, Baumann T, Scaramucci T, Aranha ACC, Carvalho TS. Chemical and physical factors of desensitizing and/or anti-erosive toothpastes associated with lower erosive tooth wear. Sci Rep 2017;7(1):17909

24 Saffarpour M, Asgartooran B, Tahriri MR, Savadroudbari MM, Khabazkhoob M. Effect of modified 45s5 bioglass on physical and chemical properties of bleached enamel. Braz J Oral Sci 2019;18(1):1-12

25 Attia ML, Cavalli V, do Espírito Santo AM, et al. Effects of bleaching agents combined with regular and whitening toothpastes on surface roughness and mineral content of enamel. Photomed Laser Surg 2015;33(7):378-383
26 Joiner A,Schäfer F, Naeeni MM, Gupta AK,Zero DT. Remineralisation effect of a dual-phase calcium silicate/phosphate gel combined with calcium silicate/phosphate toothpaste on acid-challenged enamel in situ. J Dent 2014;42(Suppl 1) :S53-S59

27 Hornby K, Ricketts SR, Philpotts CJ, Joiner A, Schemehorn B, Willson R. Enhanced enamel benefits from a novel toothpaste and dual phase gel containing calcium silicate and sodium phosphate salts. J Dent 2014;42(Suppl 1):S39-S45

28 Li X, Wang J, Joiner A, Chang J. The remineralisation of enamel: a review of the literature. J Dent 2014;42(Suppl 1) :S12-S20

29 Worschech CC, Rodrigues JA, Martins LRM, Ambrosano GMB. In vitro evaluation of human dental enamel surface roughness bleached with $35 \%$ carbamide peroxide and submitted to abrasive dentifrice brushing. Pesqui Odontol Bras 2003;17(4):342-348

30 Sa Y, Sun L, Wang Z, et al. Effects of two in-office bleaching agents with different $\mathrm{pH}$ on the structure of human enamel: an in situ and in vitro study. Oper Dent 2013;38(1):100-110 